\section{DIAPHRAGMATIC HERNIAS}

There are two general types of diaphragmatic hernias, namely, the acquired and the congenital.

In a total of $2 \% 6$ reports of cases compiled by Lacher, ${ }^{3}$ $11 \%$ were congenital; the remaining 159 were acquired; of Leichtenstein's 252 cases, ${ }^{4} 224$ were acquired, while 28 were congenital.

Acquired hernia, or rupture of the diaphragm, is therefore the more common type. The etiologic factors are trauma and pathologic perforations due to suppuration around the diaphragm.

Congenital hernia may be subdivided into false and true hernia:

1. False hernia, in which the displaced viscera are not covered by a hernial sac, is more frequent than the true form; in 117 cases, 92 were of this variety. Ther are more frequent on the left side, and in the muscular rather than the tendinous portions of the diaphragm. All of these were into the pleural cavities. The case which I report is a type of false hermia very rarely encountered, namely, a hernia directly into the pericardial cavity and having no communication with the pleural sacs.

2. True hernia, in which the abdominal organs are covered by a hernial sac of diaphragm, or peritoneum, or both, is quite rare.

I report this case on account of its great rarity, as I am unable in a fairly careful search of the literature to find mention of any similar case. It is also of interest because of the age the individual reached.

I thank Dr. Daniel Elliott, coroner's physician, and Dr. H. F. Cook, on whose service the patient died, for the privilege of performing autopsy and for the clinical history.

\section{MYXEDEMA: REPORT OF A CASE SAMUEL E. SIMMONS, A.B., M.D.} SACRAMENTO, CALIF.

Patient.-C. L. was born March, 1870, of American parents, on a Yuba county ranch. His paternal grandfather, from Yorkshire, Eng., lost his life by drowning; his paternal grandmother died at 84 of senility; his maternal grandfather and grandmother died at 84 and 89 , respectively, presumably of senility. The patient's father died at 54 of "spinal paralysis" after several years' invalidism. His mother, born in Baltimore, died at 58 of sarcoma of the ileum. He has two brothers living; one is well, the other suffers occasionally from "petit mal;" one brother died at nine years of age, the result of epilepsy of traumatic origin; one sister is alive and apparently normal in every respect.

History.-The patient had measles and whooping cough in childhood. He attended school until he was 12 years of age, when he was vaccinated; the lesion caused thereby refused to heal for six months, according to the family; and they attributed his subsequent illness to this. He left school, having previously been considered a bright child; his color changed, and he lost interest in the sports of boys of an equal age. He preferred to sit quietly, and when read to would comprehend about three words in ten; he stopped growing, and, on account of the color and a peculiar puffiness, was treated for "dropsy." By his family and friends his condition was considered to be simply one of "stunted growth." IIis mother noted at this time that if she told him to stay in one place until her return, no matter if she stayed away the entire day, she would always find that he had remained in the place and position in which she left him.

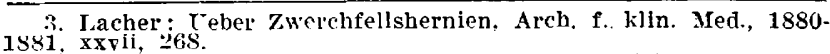

4. Leichtenstein : Ziemssen's Cyclopedia of Medicine, vii.
Examination-At office, Dec. 20, 1906: The patient's age was 36 ; height, 54 inehes; weight, 74 pounds; pulse 50 , poor volume and tension; temperature, taken with three different clinical thermometers at this visit, was 94 . The hair on the

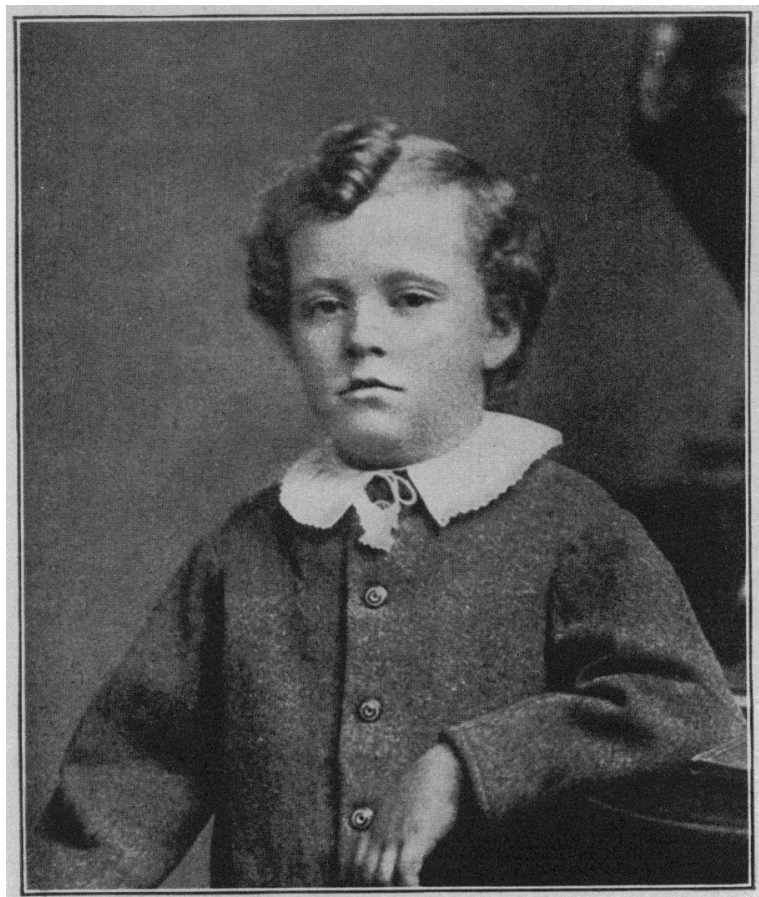

Fig. 1.-Patient at 5 years.

head was scanty and coarse; the hair on the eyebrows, hardly more than lanugo; the entire face, large and expressionless; the upper lids, swollen and baggy; the lower lids, less so, but did not pit on pressure. The skin was dry and harsh, and

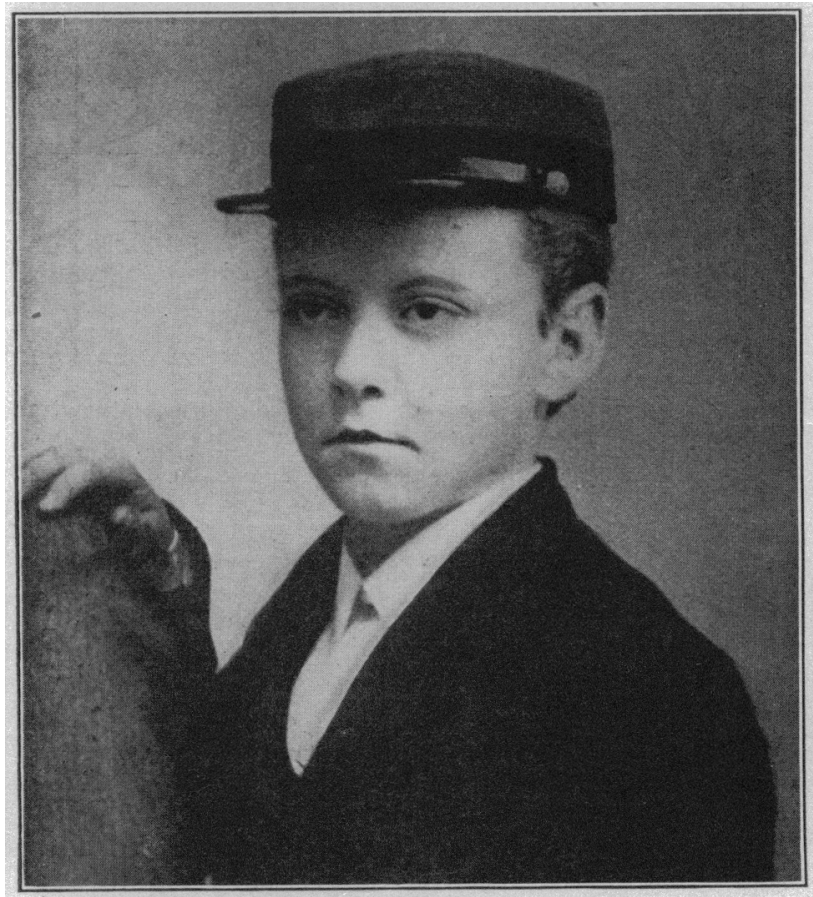

F'ig. 2.-Patient at 10 years.

showed a color between that of jaundice and that of pernicious anemia; the sclera clear. The patient stated that he never ferspired. The nose was broad and flat; the lips thick; no hair noted; the patient never shaved. The mucous membranes were pale; the tongue normal. The voice was puerile; the 
thyroid gland could not be felt ; the sublingual region, also the supraclaricular and infracluvicular spaces, were filied witl? flattened broad masses, of a consistency resembling "dairy cheese." Everywhere the skin seemed dry and adherent to the underlying tissue. The heart and lungs were normal; the ab. domen negative; the pubic hair absent: the sexual organs fairly well developed. The specific gravity of the urine, 1018; no albumin or sugar. The hands were puffy and chubbs: The blood was not examined at this time. The patient wa. not observant: answered questions slowly and with hesitation: aid not care to study or to read: occupied himself with very light "chores" around a country place. He had no headaches; his appetite was variable.

Treatment.-The diagnosis was myxedema, and the treatment for this condition was at once instituted. Armour's thyroid tablets, each of which is the equivalent of two grains ot the desicated gland, or Burroughs and Wellcomes tablet. each of which is equivalent to tive grains of the fresh healthy gland of the sheep, were administered throughout the course of the disease. Sometimes one vreparation was used, some-

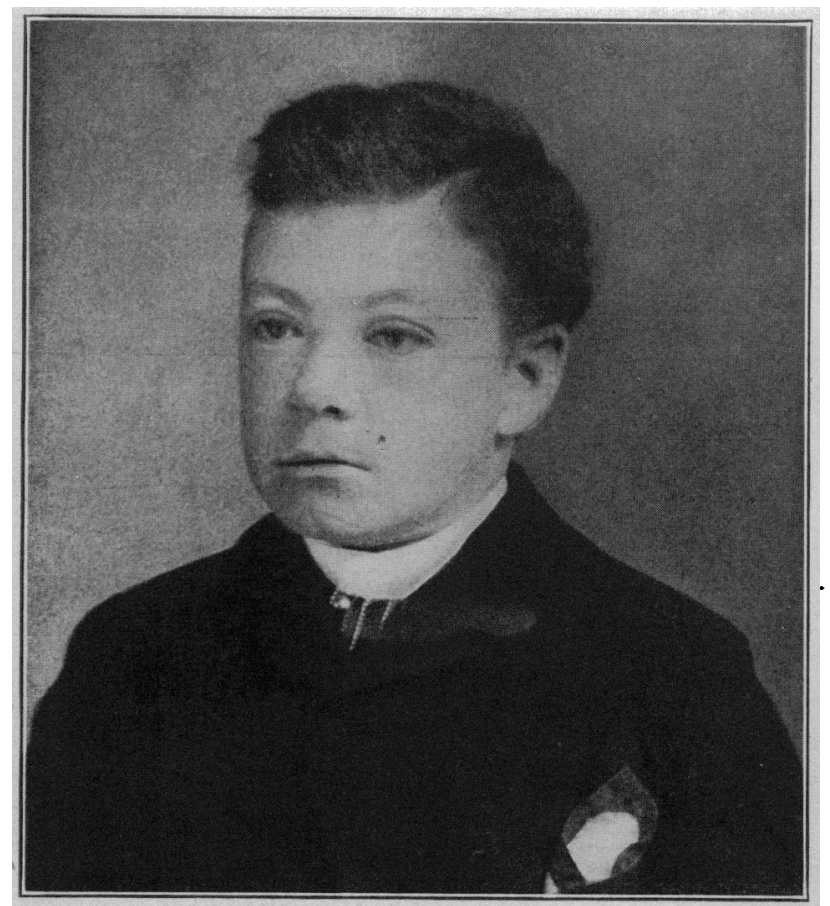

Fig. 3.-Patient at 15 years. (Note incipient myxedema.)

times the other, with no difference noted in the therapeutic potency. The treatment was begun with Armour's thyroid tablets; two a day: at the end of four weeks, the patient was taking four tablets a day.

Later History.-On Jan. $28,190 \overline{7}$, five weeks after beginning treatment, the patient reported again. The rhange in lis personal appearance, physiognomy and mentality, was most striking. The pulse was 80 : temperature but slightly below normal. A considerable increase of the hair on the liead was noted. The voice began to "break," like that of a lad at puberty: the voice had previously been similar in pitch to that commonly found in boys 8 or 10 years old. He felt the cold much lesis and noticed a change of some sort himself; he said that it felt as if it all were a new world to him. Thyroid treatment was still urged and at next visit, Feb. 20 . 1907 . the patient had an abundant growth of hair; perspired on exertion, wanted to read and play cards. and when opportunity presented "caddied" on a neighboring golf-course. His color was greatly improved; weight was stationary. From being slothful and indolent, with his greatest usefulness put to driving cows to pasture and lome again, the patient had become, in less than three months, very ambitious and worked is an errandboy in a drug store; the manager stated he was the brightest boy he ever had.
Two years lave now elapsed, and save in the initial treat. ment by the thyroid extract (which lasted two months in continuous dosage), the patient was never under treatment longer than four weeks at one time. The longest respite from thyroid therapy was for a period extending from May, 1907,

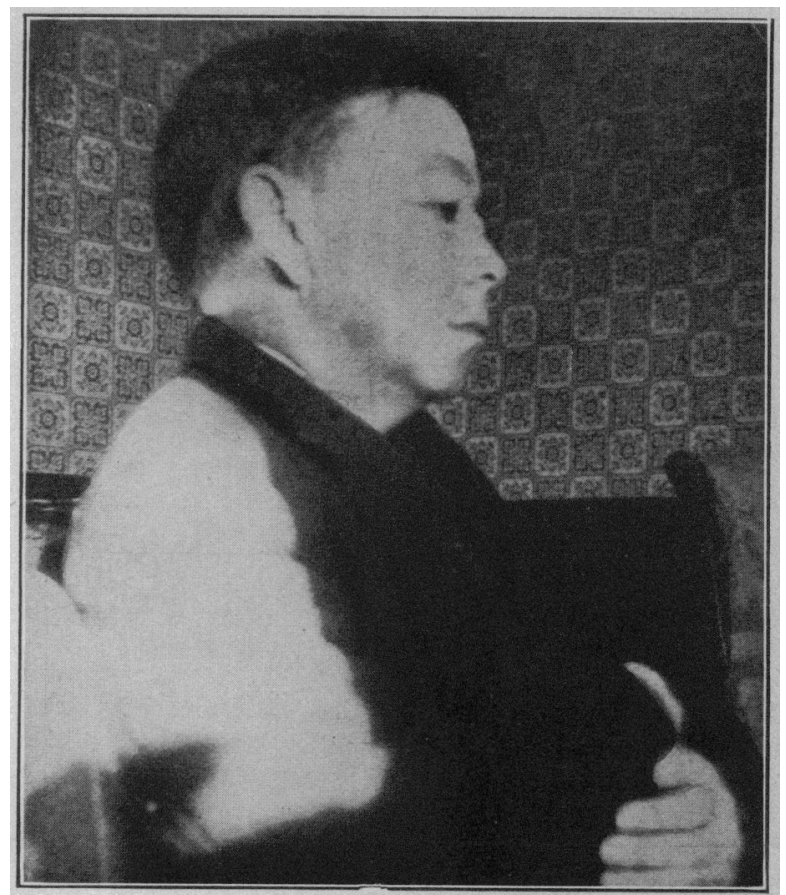

Fig. 4.--F'ditient at 36 years, jusc before beginning thyroid treatment.

to October of same year, a period of five months, when I was in Europe; at the end of this time some of the old symptoms were again in evidence, namely, characteristic color, loss of expression, swelling and puffiness under the eyes; the men-

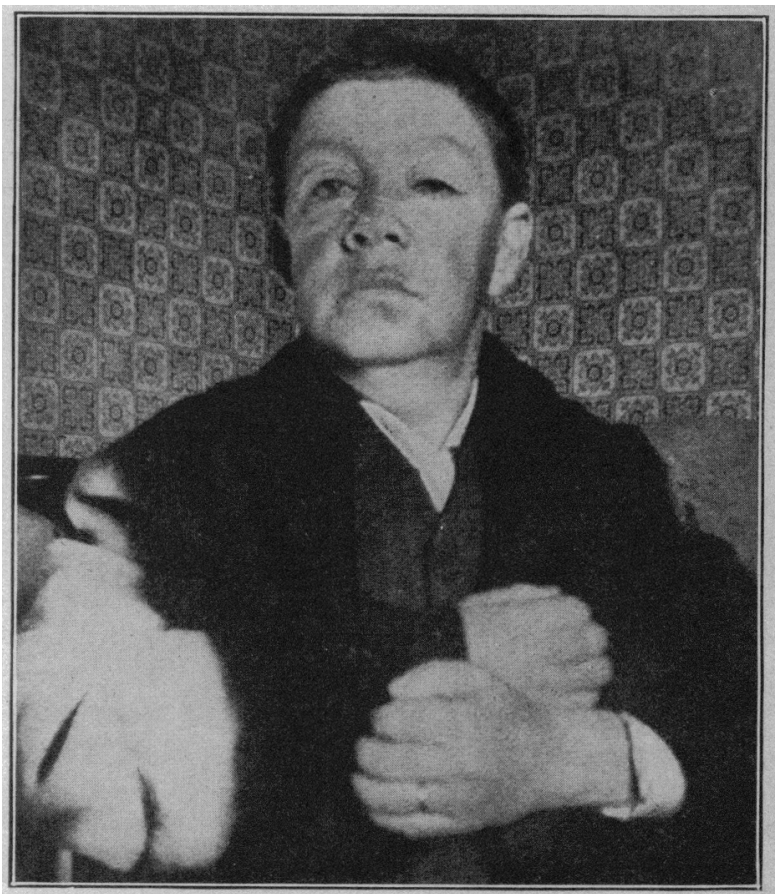

Fig. 5.-Another view of patient; same time as in Figure 4.

tality, however, continued good. The patient himself wanted to be placed under treatment again. I think that in the future the patient may be reasonably left to his own discretion in regard to treatment, for he always knows when it is 
indicated. An interesting feature of the case, aside from its rarity in these parts, is that if the patient takes more than three tablets a day, now that a cure is established, or con. tinues the treatment for more than three weeks, he soon shows

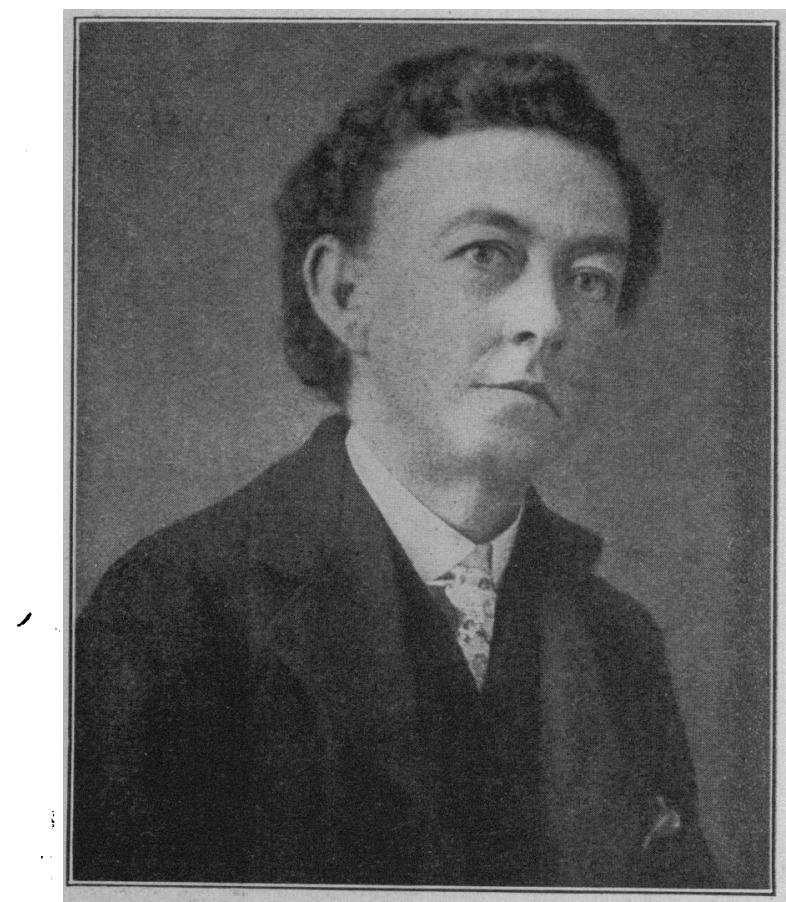

Fig. 6.-Patient six months after use of thyroid.

the symptoms of exopthalmic goiter, namely, nervousness, sieeplessness, slight exopthalmos, nausea, sometimes vomiting and general weakness.

$212 \mathrm{~J}$ Street.

\section{A CORRECTOR FOR WEAKENED FEET FOR USE AT NIGHT}

\section{J. M. B.ERRY, M.D.}

'TROY, N. $\mathbf{X}$.

The weakness and disability of the foot which culminates in the deformity commonly known as flatfoot is progressive in character. In the earliest stage of the trouble there is present simply a weakness or strain, which causes the foot to assume a weakened position favoring additional strain. The weakened position is later present constantly during activity and soon becomes habitual, and from that it is only a short step to permanent weakness and deformity.

The various stages can be enumerated as follows: (1) weakness and strain, (2) weakened position favoring more strain, (3) weak position in use, (4) habitual weak position, (5) permanent weak and deformed position.

The characteristic position of a weakened foot is the pronated or abducted position. In this position the front part of the foot is turned outward through the midtarsal joint with consequent lowering and weakening of the inner longitudinal arch. There is an apparent roiling inward and downward of the ankle, and the line of body weight drawn through the center of the knee and ankle, when prolonged over the foot, is found to be to the inner side of its normal position. All these elements of the pronated position are increased during weigit bearing and activity, and the last result of progressive weakness is the pes valgus form of clubfoot.

In the early stages of a weakened foot the weak position is assumed during weight bearing; but later the foot when at rest and relaxed, with all weight removed, falls naturally into the weak position. In later stages, the weak position becomes permanent, actual structural deformity occurs and the faulty position can be corrected only by forcible manipulation or operation.

In the treatment of weakened conditions of the feet, attention is usually directed to the use of proper braces and shoes combined with manipulation and massage. The principles of such treatment are that the brace will cause the foot to assume a proper attitude, throwing the weight of the body onto the outer side of the foot, where it belongs, while the proper shoe allows the foot to be held in a position where it is least subject to strain and can work most efficiently. Manipulation, massage, ribration, etc., limber up the foot, relieve pain and soreness and give strength.

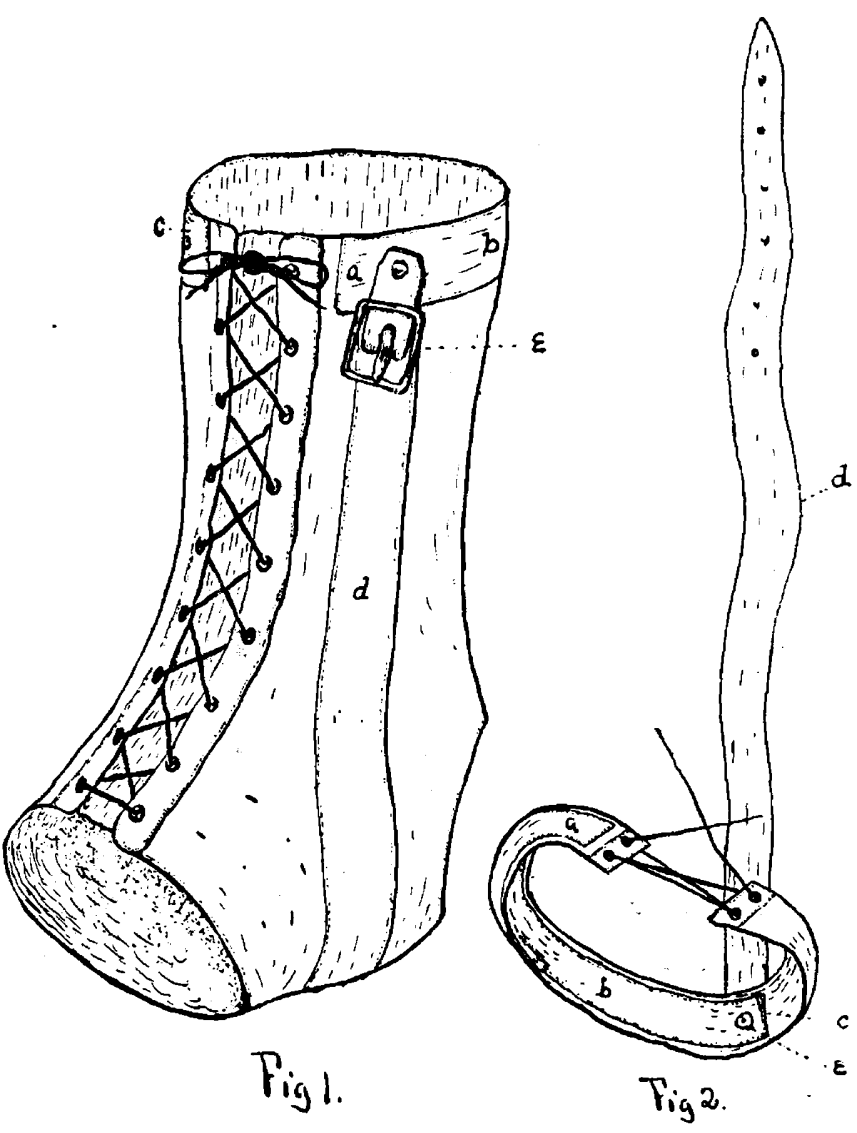

Fig. 1.-An ankle support of soft leather, cut away at the heel and laced up the front, with a band $(a, b, c)$ of thin spring brass, leather covered. encircling the top of the support. A strip of thin spring brass $(d)$, leather covered, is riveted to and extends from one end of the encircling band down the side of the ankle under the heel and up the other side, fastening to the other end of the encircling band. A buckle (e) is riveted through the of brass and the ankle support

Fig. 2,- A band to encircle the waist of the foot. For the adult foot this should be $1 \frac{1 / 4}{\mathrm{in}}$. wide. It is made to lace over the top of the foot. A strap (d) is riveted to the encircling band at corresponding to the inner and under surface of the foot.

One factor, however, is often neglected, but is of great importance in all orthopedic work in connection with deformities. I refer to the influence of position during sleep. This is of especial importance in children in whom there is the added influence of growth. 